\title{
Dispensing practices for anti-malarials in the La Nkwantanang-Madina municipality, Greater Accra, Ghana: a cross-sectional study
}

Charles Enyaah Amankwa ${ }^{*}$ (D), Harriet Affran Bonful ${ }^{2}$, Kofi Agyabeng $^{3}$ and Priscillia A. Nortey ${ }^{1}$

\begin{abstract}
Background: Despite recent strides made towards reducing the emergence of artemisinin resistance, inappropriate dispensing practices for anti-malarials in both private and public sectors affect treatment outcomes negatively. In Ghana, private retail pharmacies are the most accessible health facilities for managing diseases of common occurrence. However, there is growing concern about the number of patients harmed by dispensing errors in the management of malaria in retail pharmacies. Although considerable work has been done in this area, several questions regarding dispensing practices remain unanswered. This study, therefore, sought to investigate the predictors of appropriate dispensing practices for anti-malarials in community pharmacies in the La Nkwantanang-Madina municipality of Greater Accra, Ghana.

Methods: A cross-sectional analytic study was conducted in sixty-one randomly selected community pharmacies in the La Nkwantanang-Madina. Data from 230 clients and 106 dispensers were analysed. It was checked for internal consistency and completeness then entered and analysed using STATA I/C version 14.0. Frequencies, Chi square tests, and logistic regression analyses were conducted, accounting for clustering.

Results and discussion: Of the 106 dispensers interviewed, $71.4 \%$ were medicine counter assistants. The mean age of dispensers was 30.4 years (SD 8.8). Over $88.0 \%$ of clients were advised to complete the full course of their antimalarials. However, the 8-h loading dose principle for artemether-lumefantrine was not explained to $88.3 \%$ of the clients. More than half of the clients (52.2\%) were given appropriate dispensing information on anti-malarial use. Most clients (66.1\%), were dispensed anti-malarials without malaria tests. Dispensers with more than a 10-years experience were less likely to dispense artemisinin-based combinations appropriately relative to dispensers with less than 2 years experience $(A O R=0.04,95 \% \mathrm{Cl} 0.002-0.802 \mathrm{p}$-value $=0.036$ ) while pharmacy interns were about 19 times more likely $(A O R=18.5,95 \% \mathrm{Cl} 1.40-245.6 \mathrm{p}$-value $=0.03)$ to dispense artemisinin-based combinations appropriately compared to pharmacists.
\end{abstract}

Conclusion: Dispensing practices for anti-malarials is unsatisfactory. There is a need to enforce existing legislation with educational programmes directed towards dispensers especially those with more than 10 years experience. Specific adherence to the World Health Organization Test, Treat and Track initiative should be encouraged to ensure effective use of anti-malarials.

Keywords: Dispensing practice, Anti-malarials, Dispensers, Clients, Community pharmacies, Ghana

\footnotetext{
*Correspondence: amankwa45@gmail.com

1 Department of Epidemiology and Disease Control, School of Public

Health, University of Ghana, Legon, P.O Box LG 13, Accra, Ghana

Full list of author information is available at the end of the article
} 


\section{Background}

The accurate use medicines play an important role in healthcare delivery. The provision of appropriate medicines can help alleviate symptoms, prevent recurrence of disease and restore patient's health. Nonetheless, inappropriate use of medicines remains a major public health issue globally $[1,2]$.

In developing and low middle income countries, there has been considerable evidence of inappropriate drug use due to poor dispensing practices, inadequate package labelling and poor instruction given to clients on usage of medicines [3, 4].

In contrast to the developed regions, private retail pharmacies and Licensed Chemical Shops play an important role in promoting access to basic health services in sub-Saharan Africa. In Ghana, for example, private retail pharmacies and Licensed Chemical Shops, who are registered suppliers of specific over-the-counter medicines are the most accessible health facilities available for managing commonly occurring diseases [5]. Empirical studies have shown that the majority of families seek treatment for mild febrile diseases in retail pharmacies as compared to public health facilities [6,7]. Their operations are regulated by the Pharmacy Council (PC) of Ghana under the Health Professions Regulatory Bodies Act 857 [8]. Community pharmacies are typically managed by pharmacists (individuals who hold a degree in pharmacy, completed the required internship programme and passed professional qualifying examination) and other pharmaceutical support staff; Medicine Counter Assistants (MCA-support staff trained to complement the role of pharmacy technicians, owing to acute shortage of the technicians) and pharmacy technicians.

Retail pharmacies are patronized primarily because they are readily accessible, have longer opening hours and clients may spend less time to be served compared to the public health facilities $[5,9,10]$. However, they are poorly monitored and may not be operating professionally [1012]. In a study conducted by Buabeng in 2010, an alarming $77 \%$ of patients used incorrect dosage or did not complete the course of their anti-malarials [13]. The same study showed that (54\%) of the patients who purchased from community pharmacies took their anti-malarials inappropriately possibly due to poor dispensing information [13]. Other researchers have rather observed that a greater proportion of patients had informed understanding of adverse effects compared to 'how to use' anti-malarials [11, 14]. These point to the importance of adequate dispensing and its pivotal role in preventing medication use errors $[15,16]$.

The dispensing process forms an integral part of the quality use of medicines and is the core professional role of a pharmacist. It ensures the safe and effective provision of medication to the general public. Dispensing involves all activities from the receipt of the prescription to the time the medicine is issued out to the patient [15]. The role of the pharmacist has traditionally been to provide patients with appropriate pharmaceutical care, to maintain the quality of pharmaceutical products and to ensure that patients take their medicines rationally $[5,8,10,11,13]$.

In recent times, pharmacists' role has evolved to advising physicians and other health professionals about drug therapy, its adequacy, side effects and possible interactions. In the community pharmacy setting, however, pharmacists and other support staff may not have the opportunity to interact with physicians and therefore, treat their clients empirically $[13,17]$. This may have dire effects on patients once vital information is missed and often resources involved in patient care prior to dispensing may be wasted.

The introduction of rapid diagnostic testing (RDT) in the private sector in Ghana has made it easier for dispensers in community pharmacies to diagnose malaria definitively and treat confirmed malaria cases. However, in most malaria endemic areas, oral anti-malarials purchased from retail outlets are mainly obtained through client requests without laboratory confirmation $[6,18,19]$. Therapy initiated without conclusive test outcomes may not only accelerate artemisinin resistance but lead to the possible progression and aggravation of the actual cause of disease [17, 20-23].

Evidence from a cross-sectional survey and other studies point to a possible link between poor dispensing practices and its effect on anti-malarial resistance [24-26]. There is, therefore, a need for continuous assessment of the quality of dispensing of anti-malarials as this will inform policy makers and the National Malaria Control Programmme (NMCP) on areas to be targeted during the roll-out of interventions. Although considerable work has been done in this area, past studies on dispensing practices have primarily focused more on dispensing in public health facilities, understanding the role of pharmacists, assessing staff/patient knowledge, policy guidelines adherence among many others [13, 16, 23, 27-29].

However, there is limited information on dispensing practices among community pharmacies especially in the Greater-Accra region of Ghana. This study aims to address that gap by assessing factors associated with dispenser's practices for anti-malarials in the La Nkwantanang-Madina municipality.

\section{Methods}

The study was conducted in La Nkwantanang-Madina located in the Greater Accra Region, one of the ten administrative regions in Ghana at the time of the study. La Nkwantanang-Madina is located on the south-eastern part of the country along the Gulf of Guinea. It is estimated to have a population of 111,926 representing $2.8 \%$ of the region's total population [30]. Pharmaceutical 
services in the district are delivered in private, public, quasi-governmental health centers and mission facilities. The provision of pharmaceutical care in the health delivery system in the municipality of La NkwantanangMadina is considered to be critical and is dominated by the private sector. The study population included dispensers at post in retail community pharmacies and their clients who had purchased oral anti-malarials for use and were exiting from the pharmacies. Pregnant women and individuals with cognitive disabilities who had purchased anti-malarials were excluded from the study.

This study employed an analytical cross-sectional approach among 61 selected community pharmacies in La Nkwantanang-Madina, from May to July 2017. A total of 122 retail community pharmacies and 36 wholesale outlets were obtained from Pharmacy Council, Ghana. This study employed a simple random sampling technique to select 61 community pharmacies, excluding wholesalers and licensed chemical shops. Data were gathered from three sources: dispensers, clients, and pharmacies.

Questionnaires were administered for data collection. The client and dispensers' questionnaires were adapted from the WHO modified paper on good dispensing practices, as well as Training Manual for Licensed Chemical Sellers in Ghana [16]. Data obtained from respondents were collected, reviewed for completeness and entered using EpiData (Version 3.1). Double data entry was done to minimize errors and ensure the reliability of data collected.

The clients' questionnaire captured data on age, gender, educational level, religion, marital status, National Health Insurance (NHI) registration status, rapid diagnostic test (RDT) check, client's occupation, purchased drugs and dispensing information. Information on the number of times Pharmacy Council had visited the pharmacy within the last 6 months, availability of reference materials on Malaria Case Management (MCM) and availability of MCM wall chart were obtained from the dispensers in their respective pharmacies.

The client and dispenser data were merged and checked for internal consistency and completeness using simple summary statistics of the selected variables. Age of respondents (both dispensers and clients) were measured as completed years. Frequencies were used to describe the sociodemographic characteristics of dispensers and clients. Where there was evidence of skewness in the data, means were estimated for continuous variables after log transformation.

The dependent variable, dispensing practice was measured as a binary ordinal categorical variable (appropriate and inappropriate dispensing practices) (Table 1). This was assessed based on 13 key indicators for measuring dispensing practices (Table 4) [20, 27].
Table 1 Dispensing practice classification

\begin{tabular}{ll}
\hline Score $(\mathbf{n}=\mathbf{1 3})$ & Dispensing practice \\
\hline Less than 9 & Inappropriate \\
At least 9 & Appropriate \\
\hline
\end{tabular}

Chi square tests of associations were used to determine associations between the independent and independent categorical variables. Fisher's exact tests were used when sample sizes were found to be small ( $<5$ per cell). Univariable and stepwise multivariable logistic regression analyses were performed to determine the predictors of dispensing practices at 95\% confidence level and $\alpha$-value of 0.05 .

\section{Results}

Overall, client sample size of 248 and 106 dispensers were obtained after data validation. However, there were 18 missing values in the client dataset. Therefore, 230 and 106 completed questionnaires were obtained for client and dispenser data, respectively.

Table 2 shows the characteristics of dispensers in community pharmacies at the time of the survey. Although hundred and twenty-four (124) dispensers initially consented to partake in the study, only a hundred and six (106) completed questionnaires were obtained in the 61 pharmacies visited. Females constituted $72 \%$. The mean age of these dispensers was $30.4(\mathrm{SD}=8.8)$ years ranging from 18 years to 70 years.

The characteristics of the study participants (clients) are presented in Table 3. More than half of the clients $(60.9 \%)$ were females. The mean age was $33.70(\mathrm{SD}=10.3)$ years and ranged from 15 years to 69 years. The majority (53.6\%) were married. About thirty-nine percent (38.7\%) had completed secondary school whereas primary and tertiary had nearly equal proportions of $25.0 \%$ and $25.4 \%$ respectively. Seventy-two (29.4\%) clients were traders while $26.6 \%$ were artisans (Table 3 ).

More than half (58\%) of the clients were given accurate directions on the use of their ACT's with $88.7 \%$ being advised to complete the full course. However, most dispensers $(88.3 \%)$ did not explain the 8 -h loading dose principle to their clients (Table 4).

Chi square test for trends (Table 5) showed significant associations between each of the following variables: NHIS status (chi $=5.69, p<0.05)$, dispenser's marital status (chi $=6.55, p<0.05$ ), access to reference materials $(\mathrm{chi}=9.59, p<0.05)$, type of recommender $(\mathrm{chi}=16.54$, $p<0.05)$, awareness of guidelines (chi $=5.38, p<0.05)$ and dispensing practices.

A crude analysis of the association between dispensing practices and the predictor variables showed that marital status, access to reference materials, dispenser's 
Table 2 Socio-demographic characteristics of dispensers in community retail pharmacies in La NkwantanangMadina-2017

\begin{tabular}{|c|c|c|}
\hline Characteristics & Frequency $(n=106)$ & Percentage (\%) \\
\hline \multicolumn{3}{|l|}{ Sex } \\
\hline Male & 34 & 32.1 \\
\hline Female & 72 & 67.9 \\
\hline Age (mean, sd) & $(30.4,8.8)$ & \\
\hline \multicolumn{3}{|l|}{ Age group (years) } \\
\hline $15-24$ & 21 & 19.8 \\
\hline $25-34$ & 55 & 51.9 \\
\hline $35-44$ & 22 & 20.8 \\
\hline$>45$ & 8 & 7.6 \\
\hline \multicolumn{3}{|l|}{ Marital status } \\
\hline Single & 69 & 65.1 \\
\hline Married & 37 & 34.9 \\
\hline \multicolumn{3}{|l|}{ Highest level of education } \\
\hline None & - & - \\
\hline Primary/elementary & 1 & 0.9 \\
\hline Secondary & 30 & 28.3 \\
\hline Tertiary & 73 & 68.9 \\
\hline Vocational/technical & 2 & 1.9 \\
\hline \multicolumn{3}{|l|}{ Religion } \\
\hline Muslim & 3 & 2.8 \\
\hline Christian & 103 & 97.2 \\
\hline \multicolumn{3}{|l|}{ Ethnicity } \\
\hline Ewe & 19 & 17.9 \\
\hline Akan & 54 & 50.9 \\
\hline Ga/Adangme & 29 & 27.4 \\
\hline Northerner & 4 & 3.8 \\
\hline Professional category & $(n=97)$ & \\
\hline Pharmacist & 14 & 14.4 \\
\hline M.C.A & 71 & 73.2 \\
\hline Pharmacy technician & 3 & 3.1 \\
\hline Pharmacist Intern & 8 & 8.3 \\
\hline Other (manager/owner) & 1 & 1.0 \\
\hline
\end{tabular}

awareness of guidelines, National Health Insurance Scheme registration status and number of supervisory visits within the last 6 months were associated with the outcome of dispensing practices. However, adjusting for all other variables, dispenser's age, level of education, professional category and level of experience were significant predictors of dispensing practices (Tables 5,6 ).

Pharmacist interns were 18.5 times more likely to dispense anti-malarials appropriately compared to practicing pharmacists (AOR 18.50, 95\% CI 1.40-245.6; $p<0.05)$. Also, relative to dispensers with less than 2 years working experience, dispensers with more than 10 years' experience were less likely to dispense
Table 3 Socio-demographic characteristics of clients who patronize retail pharmacy services in the La Nkwantanang-Madina-2017

\begin{tabular}{|c|c|c|}
\hline Characteristics & $\begin{array}{l}\text { Frequency } \\
(n=248)\end{array}$ & $\begin{array}{l}\text { Percentage } \\
(\%)\end{array}$ \\
\hline \multicolumn{3}{|l|}{ Sex } \\
\hline Male & 96 & 38.7 \\
\hline Female & 151 & 60.9 \\
\hline Age (mean, sd) & $(33.7,10.3)$ & - \\
\hline \multicolumn{3}{|l|}{ Marital status } \\
\hline Single & 102 & 41.1 \\
\hline Married & 133 & 53.6 \\
\hline Separated/divorced & 5 & 2.0 \\
\hline Widow/widower & 8 & 3.2 \\
\hline \multicolumn{3}{|c|}{ Highest level of education } \\
\hline None & 8 & 3.2 \\
\hline Primary/elementary & 62 & 25.0 \\
\hline Secondary & 96 & 38.7 \\
\hline Tertiary & 63 & 25.4 \\
\hline Vocational/technical & 19 & 7.7 \\
\hline \multicolumn{3}{|l|}{ Religion } \\
\hline Muslim & 35 & 14.1 \\
\hline Christian & 211 & 85.1 \\
\hline Traditional & 2 & 0.8 \\
\hline \multicolumn{3}{|l|}{ Ethnicity } \\
\hline Ewe & 64 & 25.8 \\
\hline Akan & 100 & 40.3 \\
\hline Ga/Adangme & 43 & 17.3 \\
\hline Northerner & 36 & 14.5 \\
\hline Other & 5 & 2.0 \\
\hline \multicolumn{3}{|l|}{ Occupation } \\
\hline Trader & 72 & 29.0 \\
\hline Artisan $^{a}$ & 66 & 26.6 \\
\hline Professional ${ }^{b}$ & 34 & 13.7 \\
\hline Office worker ${ }^{c}$ & 27 & 10.9 \\
\hline Unemployed & 11 & 4.4 \\
\hline Student & 35 & 14.1 \\
\hline Other & 3 & 12.0 \\
\hline
\end{tabular}

a To a worker in a skilled trade especially one that involves making things by hand. Eg hairdressers, painters, etc.

b Includes skilled professionals such as nurses, teachers, etc.

c Mainly people who work in offices e.g. bankers

Artemisinin Combination Therapy (ACT's) appropriately (AOR 0.04, 95\% CI 0.002-0.802 $p<0.05$ ). The most dispensed anti-malarial was artemether-lumefantrine (83.55), while atovaquone-proguanil was the least dispensed (Fig. 1). 
Table 4 Distribution of areas of assessment during dispensing and post-dispensing advice

\begin{tabular}{|c|c|c|}
\hline Areas of assessment (advise) & Frequency $(n=248)$ & Percentage (100\%) \\
\hline \multicolumn{3}{|c|}{ Advice on how to take anti-malarials } \\
\hline Accurate direction & 103 & 58.5 \\
\hline Inaccurate direction & 145 & 41.5 \\
\hline \multicolumn{3}{|l|}{ Taking after meals } \\
\hline After meals & 237 & 95.6 \\
\hline Before meals & 11 & 4.4 \\
\hline \multicolumn{3}{|l|}{ Completion of full course } \\
\hline Advised & 220 & 88.7 \\
\hline Not advised & 28 & 11.3 \\
\hline \multicolumn{3}{|l|}{ Risk of side effects } \\
\hline Advised & 53 & 21.4 \\
\hline Not advised & 195 & 78.6 \\
\hline \multicolumn{3}{|l|}{ Labelling } \\
\hline \multicolumn{3}{|l|}{ Labelling in ink } \\
\hline Yes & 230 & 92.7 \\
\hline No & 18 & 7.3 \\
\hline \multicolumn{3}{|l|}{ Clear instruction } \\
\hline Clear & 216 & 87.1 \\
\hline Not clear & 32 & 12.9 \\
\hline \multicolumn{3}{|l|}{ Legibility to client } \\
\hline Legible & 223 & 89.9 \\
\hline Illegible & 25 & 10.1 \\
\hline \multicolumn{3}{|l|}{ Label captured } \\
\hline \multicolumn{3}{|l|}{ Quantity of drugs dispensed } \\
\hline Yes & 226 & 91.1 \\
\hline No & 22 & 8.9 \\
\hline \multicolumn{3}{|l|}{ Frequency of administration } \\
\hline Yes & 219 & 88.3 \\
\hline No & 29 & 11.7 \\
\hline \multicolumn{3}{|l|}{ Exact time to take the drug } \\
\hline Yes & 29 & 11.7 \\
\hline No & 219 & 88.3 \\
\hline \multicolumn{3}{|l|}{ Duration of administration } \\
\hline Yes & 191 & 77.0 \\
\hline No & 57 & 23.0 \\
\hline
\end{tabular}

Assessment was from clients exit interviews

\section{Discussion}

The over-consumption of oral anti-malarials in the private drug retail sector is a major threat to the health of the people. With concerns of overdiagnosis of malaria, poor dispensing and subsequent increase in antimicrobial resistance, key strategic options such as the distribution of rapid diagnostic test kits, peer education and training of dispensers in the private retail sector was done to scale up malaria prevention and treatment [28, 31, 32].
This study showed that dispensing practices for antimalarials is generally unsatisfactory at the study site. With about $48 \%$ of dispensers (47.8\%) dispensing antimalarials inappropriately, a high fraction of inappropriate dispensing practices was similarly observed by Alotaibi and Abdelkarim in a survey conducted in Dawadmi, Saudi Arabia [33]. Consumers perceived that pharmacists $(48 \%)$ do not give enough counselling about their medications [33]. The observation could, however, be attributed to time constraints either from the service provider or the client [34]. In connection to this, some authors 
Table 5 Chi square test of association of socio-demographic characteristics of dispensers and dispensing practices

\begin{tabular}{|c|c|c|c|c|c|c|}
\hline \multirow[t]{3}{*}{ Variables } & \multicolumn{4}{|c|}{ Dispensing practices } & \multirow[t]{3}{*}{$x^{2}$} & \multirow[t]{3}{*}{ p-value } \\
\hline & \multicolumn{2}{|c|}{ Appropriate } & \multicolumn{2}{|c|}{ Inappropriate } & & \\
\hline & Frequency & $\%$ & Frequency & $\%$ & & \\
\hline \multicolumn{7}{|l|}{ Age group } \\
\hline $15-24$ & 14 & 11.6 & 11 & 10.0 & 8.05 & 0.184 \\
\hline $25-34$ & 59 & 49.2 & 58 & 52.7 & & \\
\hline $35-44$ & 29 & 24.2 & 36 & 32.7 & & \\
\hline $45+$ & 18 & 15.0 & 5 & 4.6 & & \\
\hline Total & 121 & 100.0 & 110 & 100.0 & & \\
\hline Sex & \multicolumn{2}{|l|}{$N=120$} & \multicolumn{2}{|l|}{$N=110$} & & \\
\hline Male & 34 & 28.3 & 33 & 30.0 & 0.08 & 0.802 \\
\hline Female & 86 & 71.7 & 77 & 70.0 & & \\
\hline Educational level & \multicolumn{2}{|l|}{$N=120$} & \multicolumn{2}{|l|}{$N=110$} & & \\
\hline None & - & - & - & - & 1.47 & 0.577 \\
\hline Primary & 1 & 0.8 & - & - & & \\
\hline Secondary & 42 & 35.0 & 36 & 32.7 & & \\
\hline Tertiary & 76 & 63.3 & 72 & 65.5 & & \\
\hline Vocational/technical & 1 & 0.8 & 2 & 1.8 & & \\
\hline NHIS status & \multicolumn{2}{|l|}{$N=120$} & \multicolumn{2}{|l|}{$N=110$} & & \\
\hline Have NHIS & 59 & 49.2 & 37 & 33.6 & 5.69 & $0.048^{*}$ \\
\hline Not have NHIS & 62 & 51.2 & 73 & 66.4 & & \\
\hline Professional category & \multicolumn{2}{|l|}{$N=120$} & \multicolumn{2}{|l|}{$N=110$} & & \\
\hline Pharmacist & 14 & 11.8 & 15 & 13.6 & 6.51 & 0.239 \\
\hline Medicine Counter Assistant & 85 & 71.4 & 88 & 80.0 & & \\
\hline Pharmacy Technician & 6 & 5.0 & 2 & 1.8 & & \\
\hline Pharmacy Intern & 11 & 9.2 & 3 & 2.7 & & \\
\hline Other & 3 & 2.5 & 2 & 1.8 & & \\
\hline Years of experience & \multicolumn{2}{|l|}{$N=119$} & \multicolumn{2}{|l|}{$N=110$} & & \\
\hline$<2$ years & 28 & 25.0 & 14 & 14.6 & 3.73 & 0.535 \\
\hline $3-5$ years & 41 & 36.6 & 39 & 40.6 & & \\
\hline $6-9$ years & 31 & 27.7 & 29 & 30.2 & & \\
\hline$>10$ years & 12 & 10.7 & 14 & 14.6 & & \\
\hline Marital status & \multicolumn{2}{|l|}{$N=112$} & \multicolumn{2}{|l|}{$N=96$} & & \\
\hline Single & 82 & 68.3 & 57 & 51.8 & 6.55 & $0.046^{*}$ \\
\hline Married & $\begin{array}{l}38 \\
N=120\end{array}$ & 31.7 & $\begin{array}{l}53 \\
N=110\end{array}$ & 48.2 & & \\
\hline \multicolumn{7}{|l|}{ Access to wall chart } \\
\hline Yes & 13 & 10.8 & 24 & 21.8 & 5.13 & 0.095 \\
\hline No & 107 & 89.2 & 86 & 78.2 & & \\
\hline Access to reference material & \multicolumn{2}{|l|}{$N=120$} & \multicolumn{2}{|l|}{$N=110$} & & \\
\hline Yes & 53 & 44.2 & 71 & 64.5 & 9.59 & $0.02^{*}$ \\
\hline No & 67 & 55.8 & 39 & 35.5 & & \\
\hline Supervisory visits & $N=120$ & & $N=110$ & & & \\
\hline Once & 48 & 40.0 & 58 & 52.7 & 10.71 & 0.127 \\
\hline Twice & 40 & 33.3 & 20 & 18.2 & & \\
\hline Three times & 3 & 2.5 & 5 & 4.6 & & \\
\hline More than 3 & 3 & 2.5 & 0 & 0 & & \\
\hline Can't remember & 26 & 21.7 & 27 & 24.6 & & \\
\hline Recommender & $N=120$ & & $N=110$ & & & \\
\hline
\end{tabular}


Table 5 (continued)

\begin{tabular}{|c|c|c|c|c|c|c|}
\hline \multirow[t]{3}{*}{ Variables } & \multicolumn{4}{|c|}{ Dispensing practices } & \multirow[t]{3}{*}{$x^{2}$} & \multirow[t]{3}{*}{ p-value } \\
\hline & \multicolumn{2}{|l|}{ Appropriate } & \multicolumn{2}{|c|}{ Inappropriate } & & \\
\hline & Frequency & $\%$ & Frequency & $\%$ & & \\
\hline Dispenser & 67 & 55.8 & 63 & 57.3 & 16.54 & $0.024^{*}$ \\
\hline Relative & 16 & 13.3 & 5 & 4.6 & & \\
\hline Friend & 2 & 1.7 & 0 & 0 & & \\
\hline Self & 16 & 13.3 & 30 & 27.3 & & \\
\hline Media & 0 & 0 & 2 & 1.8 & & \\
\hline Unspecified & 19 & 15.8 & 10 & 9.1 & & \\
\hline Awareness of guidelines & $N=120$ & & $N=110$ & & & \\
\hline Yes & 112 & 93.3 & 92 & 83.6 & 5.38 & $0.019^{*}$ \\
\hline No & 8 & 6.7 & 18 & 16.4 & & \\
\hline In-service training (last 12 months) & $N=120$ & & $N=110$ & & & \\
\hline Yes & 24 & 20.0 & 36 & 32.7 & 4.86 & 0.259 \\
\hline No & 70 & 58.3 & 53 & 48.2 & & \\
\hline Can't remember & $\begin{array}{l}26 \\
N=120\end{array}$ & 21.7 & $\begin{array}{l}21 \\
N=110\end{array}$ & 19.1 & & \\
\hline
\end{tabular}

Statistically significant associations are marked with *

have indicated interruptions during dispensing; low staff strength, inadequate knowledge, lack of training and dispenser fatigue as likely causes of inappropriate dispensing practices [35]. This high rate of inappropriately dispensed ACT medicines and poor counselling if not addressed could impede progress in the fight against anti-malarial resistance in Ghana.

This study could not clearly establish an association between in-service training and dispensing practices. In contrast, several studies have associated a positive relationship between training and dispensing practices. In a study where, dispensing practice was measured as the ability to identify the recommended anti-malarial, the odds of knowing the recommended treatment was significantly higher amongst participants with health training [28].

Dispensers with more than 10 years' experience were less likely to dispense ACT appropriately (AOR $=0.04$, 95\% CI 0.002-0.802 $p$-value $<0.05$ ) while pharmacy interns were about 19 times more likely (AOR $=18.5$, 95\% CI 1.40-245.6 $p$-value $<0.05)$ to dispense ACT appropriately compared to pharmacists. Hussein and Ibrahim, in a similar study, reported that dispensers with less than one-year work experience had a better knowledge in Lahore, thus reflecting in their dispensing practices [4]. This might be linked to a greater number of graduate pharmacists with updated knowledge on the newer trends in managing diseases of common occurrence at the community level. Cordina et al. in their study asserted that younger pharmacists identified more with current trends in the practice of pharmacy relative to their colleagues [36].

The role of accurate diagnosis with the newly introduced rapid diagnostic test kits cannot be underestimated. Ansah et al., in a cluster randomized trial conducted among LCS in the erstwhile Dangme West District of Ghana, demonstrated that providing RDT's for malaria in the private drug retail sector significantly reduced dispensing of anti-malarials to patients without malaria [37]. However, some patients are not tested prior to initiation of treatment for malaria. Findings from this study reports that an overwhelming majority (66\%) of the patients were not tested before being dispensed oral anti-malarials (Fig. 2). This finding is consistent with a similar study in Tanzania which reported that about $98 \%$ of patients were treated presumptively for malaria without performing an RDT [19]. This phenomenon has been observed in the Ghanaian public health facilities as well, as other reports suggest that over $40 \%$ of patients were treated presumptively for malaria [37, 38].

Brugha and colleagues have pointed out that motivation for profit in the private health sector may compromise the quality of care and numerous crosssectional studies have attributed this phenomenon to inadequate training services for community pharmacy attendants, lack of supervision by regulatory authorities and the lack of confidence in the diagnostic test 
Table 6 Univariate and multivariate logistic regression estimates of the socio-demographic predictors of appropriate dispensing practices of dispensers

\begin{tabular}{|c|c|c|c|c|}
\hline Characteristics & Crude OR $(95 \% \mathrm{Cl})$ & p-value & Adjusted OR (95\% Cl) & $p$-value \\
\hline \multicolumn{5}{|l|}{ Age group } \\
\hline 15-24 (reference) & 1 & & 1 & - \\
\hline $25-34$ & $0.80(0.24-2.72)$ & 0.714 & $1.97(0.31-12.61)$ & 0.465 \\
\hline $35-44$ & $0.63(0.17-2.32)$ & 0.482 & $7.76(0.89-67.37)$ & 0.063 \\
\hline$>45$ & $2.82(0.53-15.10)$ & 0.218 & $15.23(25.91-5893.9)$ & $0.001^{*}$ \\
\hline \multicolumn{5}{|l|}{ Sex } \\
\hline Male (reference) & 1 & & & \\
\hline Female & $1.08(0.57-2.07)$ & 0.80 & $0.95(0.35-2.64)$ & 0.927 \\
\hline \multicolumn{5}{|l|}{ Educational level } \\
\hline None (reference) & 1 & & 1 & - \\
\hline Primary & 1 (omitted) & - & 1 (omitted) & - \\
\hline Secondary & $7.83 e-7$ & - & $8.5 e-7(4.3 e-8-1.7 e-5)$ & $0.001^{*}$ \\
\hline Tertiary & $7.03 e-7$ & - & $9.2 e-7(5.4 e-8-1.6 e-5)$ & $0.001^{*}$ \\
\hline Vocational/technical & $3.36 \mathrm{e}-7$ & - & $5.8 e-6(1.22 e-7-3 e-4)$ & $0.001^{*}$ \\
\hline \multicolumn{5}{|l|}{ Professional category } \\
\hline Pharmacist (reference) & 1 & & 1 & - \\
\hline MCA & $1.03(0.33-3.22)$ & 0.952 & $1.64(0.43-6.25)$ & 0.461 \\
\hline Pharm. Technician & $3.21(0.42-24.71)$ & 0.255 & $1.90(0.39-9.33)$ & 0.421 \\
\hline Pharm. Intern & $3.93(0.53-29.08)$ & 0.176 & $18.5(1.40-245.6)$ & $0.03^{*}$ \\
\hline Other & $1.61(0.54-4.75)$ & 0.383 & $4.91(0.40-60.40)$ & 0.208 \\
\hline \multicolumn{5}{|l|}{ Marital status } \\
\hline Single & 1 & - & 1 & - \\
\hline Married & $0.49(0.25-0.99)$ & $0.047^{*}$ & $0.20(0.040-1.01)$ & 0.051 \\
\hline \multicolumn{5}{|l|}{ NHIS status } \\
\hline Have NHIS (reference) & 1 & & 1 & \\
\hline Don't have NHIS & $0.52(0.27-0.99)$ & $0.050^{*}$ & $0.41(0.12-1.07)$ & 0.067 \\
\hline \multicolumn{5}{|l|}{ Access to wall chart } \\
\hline Yes & 1 & - & & \\
\hline No & $2.30(0.85-6.23)$ & 0.10 & $3.32(0.85-13.00)$ & 0.082 \\
\hline \multicolumn{5}{|l|}{ Experience } \\
\hline$<2$ years (reference) & 1 & - & & \\
\hline $3-5$ years & $0.53(0.19-1.49)$ & 0.219 & $0.47(0.09-2.36)$ & 0.348 \\
\hline $6-9$ years & $0.53(0.15-1.92)$ & 0.328 & $0.25(0.026-2.50)$ & 0.209 \\
\hline$>10$ years & $0.43(0.10-1.75)$ & 0.231 & $0.04(0.002-0.802)$ & $0.036^{*}$ \\
\hline \multicolumn{5}{|l|}{ Awareness of guidelines } \\
\hline Aware (reference) & 1 & & & \\
\hline Unaware & $0.37(0.15-0.86)$ & $0.022^{*}$ & $0.45(0.16-1.24)$ & 0.122 \\
\hline \multicolumn{5}{|c|}{ Access to reference material } \\
\hline Yes & 1 & - & & \\
\hline No & $2.30(1.14-4.63)$ & $0.020^{*}$ & $2.10(0.61-7.20)$ & 0.240 \\
\hline \multicolumn{5}{|l|}{ Supervisory visits } \\
\hline Once & 1 & - & 1 & \\
\hline Twice & $2.42(1.15-5.06)$ & $0.020^{*}$ & $1.35(0.38-4.84)$ & 0.636 \\
\hline Three times & $0.73(0.25-2.08)$ & 0.543 & $0.51(0.12-2.14)$ & 0.345 \\
\hline$>$ Three & 1 (omitted) & - & 1 (omitted) & - \\
\hline Can't remember & $1.16(0.55-2.50)$ & 0.688 & 1 (omitted) & - \\
\hline \multicolumn{5}{|l|}{ Recommender } \\
\hline Dispenser & 1 & - & 1 & - \\
\hline
\end{tabular}


Table 6 (continued)

\begin{tabular}{lllll}
\hline Characteristics & Crude OR $(\mathbf{9 5} \% \mathbf{C l})$ & p-value & Adjusted OR (95\% Cl) & p-value \\
\hline Relative & $3.00(1.18-7.68)$ & $0.022^{*}$ & $7.40(1.03-53.41)$ & $0.047^{*}$ \\
Friend & 1 (omitted) & - & 1 (omitted) & - \\
Self & $0.50(0.25-0.99)$ & $0.046^{*}$ & $0.20(0.07-0.53)$ & $0.002^{*}$ \\
Media & 1 (omitted) & - & 1 (omitted $)$ & \\
Unspecified & $1.79(0.66-4.85)$ & 0.248 & $3.22(0.78-13.35)$ & 0.104 \\
\hline
\end{tabular}

Statistically significant associations are marked with *

OR odds ratio
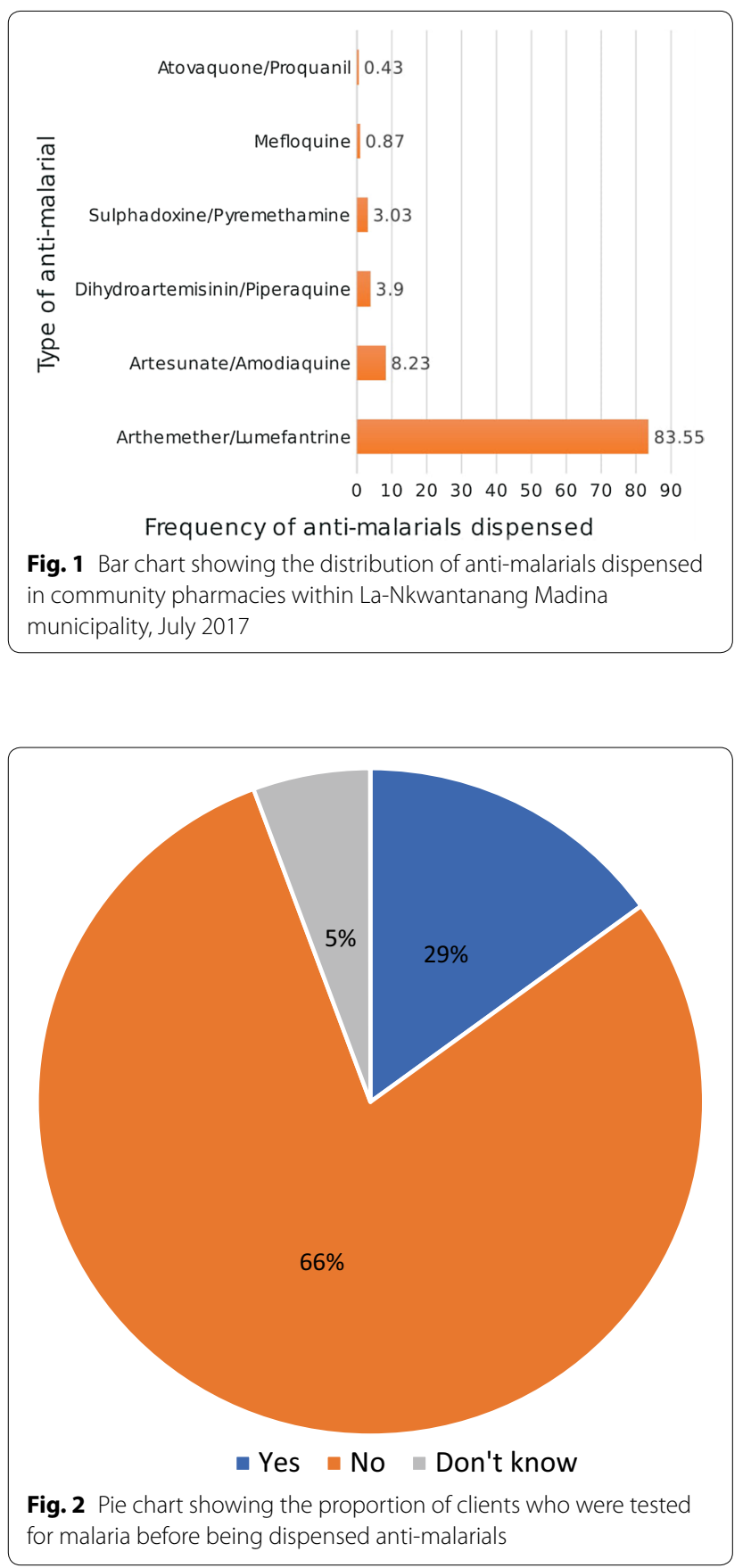

kits [39]. This finding illustrates the potential risk of malaria misdiagnosis which may accelerate the burden of anti-malarial resistance as has been recorded in South Eastern Asia [24, 26, 40]. Further research is, therefore, required to get the views and perception of dispensers. Monitoring and evaluation of training interventions may provide useful insights on dispensing practices. In so doing, pharmacists can introduce methods and strategies to expand their contribution in the dispensing process.

\section{Study limitations}

The study had some few limitations. Firstly, responses to dispensing practices and the last attendance to an in-service training may have been influenced by recall biases. Also, the cross-sectional nature of the study may limit the ability to infer causality.

The findings of this research may represent the reality in municipalities with comparable characteristics as the study site.

\section{Conclusion}

Community pharmacy dispensing practices were found to be unsatisfactory. Almost half of the clients (47.8\%) were given inappropriate dispensing information on the use of their anti-malarials. Dispensers with more than 10 years working experience were less likely to dispense ACT medicines appropriately, while pharmacy interns were more likely to dispense ACTs appropriately. In view of this, strategies to educate and update the knowledge base of all dispensers focusing on those with more than 10 years working experience may be helpful. Education should be channeled on adherence and compliance to World Health Organization's Test, Treat and Track initiative, as well to promote the appropriate use of anti-malarials.

\section{Abbreviations}

ACT: artemisinin-based combination therapy; AL: artemether-lumefantrine; Cl: confidence interval; NMCP: National Malaria Control Programme; RDT: rapid diagnostic test; LCS: Licensed Chemical Sellers; PC: Pharmacy Council; NHI: 
National Health Insurance; MCM: Malaria Case Management; MCA: Medicine Counter Assistants; AOR: adjusted odds ratio; WHO: World Health Organization.

\section{Acknowledgements}

The authors will like to thank all research field workers, regional and district health officers, the Pharmacy Council of Ghana and our study participants. We also recognize the assistance from Miss Doris Tsekpetse, a research assistant who helped with data entry. Pharm. Michael Mireku, RN. Henry Ofori-Duah and Dr. Paa Kwesi Blankson for editing and proofreading the manuscript. An abstract of this paper has been presented at the 83rd Conference of the Pharmaceutical Society of Ghana, in August 2018 with sponsorship from Mr. Charles Osei Amankwa, Ghana Revenue Authority, Ghana.

\section{Authors' contributions}

CEA was the principal investigator for this project. He played active roles in the conceptualization, design, data collection, data analysis and drafting of the manuscript. HB was actively involved in the design of the project, its analysis and contributed immensely to the reviewing manuscript. KA contributed to the analysis and reviewing of the manuscript. PAN was the project supervisor and contributed to the drafting and reviewing of the manuscript. All authors read and approved the final manuscript.

\section{Funding}

This research was solely funded by the principal investigator.

\section{Availability of data and materials}

The datasets obtained and/or analysed during the current study are not available publicly, however, it will be made available from the corresponding author on reasonable request.

\section{Ethics approval and consent to participate}

Ethical approval for the study was granted by the Ghana Health Service-Ethics Review Committee (Approval Number: GHS-ERC 83/02/17). Additional approval by way of informed consent (written consent) was obtained from dispensers, clients and the owners of retail facilities prior to data collection.

\section{Consent for publication}

\author{
Not applicable.
}

\section{Competing interests}

The authors declare that they have no competing interests.

\section{Author details}

${ }^{1}$ Department of Epidemiology and Disease Control, School of Public Health, University of Ghana, Legon, P.O Box LG 13, Accra, Ghana. ${ }^{2}$ Ghana College of Pharmacists, Cantonments, P.O Box CT10740, Accra, Ghana. ${ }^{3}$ Department of Biostatistics, School of Public Health, University of Ghana, Legon, P.O Box LG 13, Accra, Ghana.

Received: 15 April 2019 Accepted: 23 July 2019

Published online: 30 July 2019

\section{References}

1. Ofori-Asenso R, Agyeman AA. Irrational use of medicines-a summary of key concepts. Pharmacy (Basel). 2016:4:35.

2. Cameron A, Ewen M, Auton M, Agbegunde D. The worlds medicines situation: medicines prices, availability and affordability, Geneva. World Health Organization. 2011;2:32.

3. Athuraliya N, Walkom EJ, Dharmaratne S, Robertson J. Assessing medication packaging and labelling appropriateness in Sri Lanka. J Pharm Policy Pract. 2016;9:5-10.

4. Hussain A, Ibrahim MIM. Qualification, knowledge and experience of dispensers working at community pharmacies in Pakistan. Pharm Pract. 2011;9:93-100.

5. Annual Report NMCP. National Malaria Control Centre for Health Information Management. Accra. 2015;2016:1-70.

6. Buabeng KO, Duwiejua M, Dodoo ANO, Matowe LK, Enlund H. Selfreported use of anti-malarial drugs and health facility management of malaria in Ghana. Malar J. 2007;6:85.
7. Nigatu H, Dumessa E. Factors influencing the exit knowledge of patients for dispensed drugs at outpatient pharmacy of Hiwot Fana Specialized University Hospital, Eastern Ethiopia. Dove Press. 2017;11:205-12.

8. Health Professions Regulatory Bodies Act 2013, Act 857, Ghana. 2013; part IV: 1-87.

9. Stenson B, Syhakhang L, Eriksson B, Tomson G. Real world pharmacy: assessing the quality of private pharmacy practice in the Lao People's Democratic Republic. Soc Sci Med. 2001;52:393-404.

10. Iwelunmor J, Idris O, Adelakun A, Airhihenbuwa CO. Child malaria treatment decisions by mothers of children less than five years of age attending an outpatient clinic in south-west Nigeria: an application of the PEN-3 cultural model. Malar J. 2010;9:354.

11. Goodman C, Brieger W, Unwin A, Mills A, Greer G. Medicine sellers and malaria treatment in sub-Saharan Africa. Am J Trop Med Hyg. 2010;77:203-18.

12. Foster S. Treatment of malaria outside the formal health services. J Trop Med Hyg. 1995;98:29-34.

13. Buabeng $\mathrm{KO}$. The role of the pharmaceutical sector in malaria control in Ghana. 4th ed. Finland: Publications of the University of Eastern; 2010.

14. Opiyo N, Yamey G, Garner P. Subsidising artemisinin-based combination therapy in the private retail sector. Cochrane Database Syst Rev. 2016;3:CD009926.

15. Embrey M. Ensuring good dispensing practices. Manag Sci Health. 2012;28-45.

16. Thomson R, Johannes B, Festo C, Kalolella A, Taylor M, Bruxvoort K, et al. An assessment of the malaria-related knowledge and practices of Tanzania's drug retailers: exploring the impact of drug store accreditation. BMC Health Serv Res. 2018;18:169.

17. Moody A. Rapid diagnostic tests for malaria parasites. Clin Microbiol Rev. 2002;15:66-78.

18. Mensah SJA, Addai Mensah O, Nagai HN, Annani Akollor M. Evaluating access to malaria rapid diagnostic test kit and artemisinin-based combination therapy and the quality of treatment practice among over-the-counter medicine sellers at the district level in the Brong Ahafo region-Ghana. Texila Int J Clin Res. 2018:5:1-13.

19. Masanja MI, McMorrow M, Kahigwa E, Kachur SP, McElroy PD. Health workers' use of malaria rapid diagnostic tests (RDTS) to guide clinical decision making in rural dispensaries, Tanzania. Am J Trop Med Hyg. 2010;83:1238-41.

20. Lloyd W, Polage CR, Zurcher E, Owusu-Ofori A, Frimpong E, Hale D, Petti CA. Laboratory use in Ghana: physician perception and practice. Am J Trop Med Hyg. 2018;75:526-31.

21. Singer $B$, Teklahaimanot A. Background paper of the task force on major diseases and access to medicine, subgroup on malaria. 2003.

22. Reyburn H, Mbatia R, Drakeley C, Carneiro I, Mwakasungula E, Mwerinde $\mathrm{O}$, et al. Overdiagnosis of malaria in patients with severe febrile illness in Tanzania: a prospective study. BMJ. 2004;329:1212-5.

23. Rowe AK, De Leán GFP, Mihigo J, Santelli ACF, Miller NP, Van-Dnem P. Quality of malaria case management at outpatient health facilities in Angola. Malar J. 2009;8:275.

24. Abuzeid A, Elmannan A, Elmardi KA, Idris YA, Spector JM, Ali NA, et al. Anti-malarial prescribing practices in Sudan eight years after introduction of artemisinin-based combination therapies and implications for development of drug resistance. BMC Pharmacol Toxicol. 2015;16:3.

25. Bano A, Afzal M, Sarwar H, Waqas A, Kousar S, Gulzar S. Dietary knowledge, attitude and practices of diabetes patients at Services Hospital Lahore. Int J Appl Sci Biotechnol. 2017;5:227-36.

26. Noedl H, Se Y, Schaecher K, Smith BL, Socheat D. Evidence of artemisininresistant malaria in Western Cambodia. N Engl J Med. 2008;26:19-20.

27. Nkansah N, Mostovetsky O, Yu C, Chheng T, Beney J, Bond CM, et al. Effect of outpatient pharmacists' non-dispensing roles on patient outcomes and prescribing patterns. Cochrane Database Syst Rev. 2010;7:CD000336.

28. Osorio De Castro CGS, Mutis MCS, Miranda ES, Luz TCB. Dispensing and determinants of non-adherence to treatment for non complicated malaria caused by Plasmodium vivax and Plasmodium falciparum in highrisk municipalities in the Brazilian Amazon. Malar J. 2015;14:471.

29. Smith F. Community pharmacy in Ghana: enhancing the contribution to primary health care. Health Policy Plan. 2004;19:234-41.

30. La Nkwantanang. Composite Budget for 2018-2021 La NkwantanangMadina Municipal Assembly. 2018. 
31. Siringi S. Over-the-counter sale of antimalaria drugs stalls Kenyan disease strategy. Lancet. 2001;357:1862.

32. Chowdhury F, Sturm-Ramirez K, Al Mamun A, Iuliano AD, Bhuiyan MU, Chisti MJ, et al. Factors driving customers to seek health care from pharmacies for acute respiratory illness and treatment recommendations from drug sellers in Dhaka city, Bangladesh. Patient Prefer Adherence. 2017;11:479-86.

33. Alotaibi HS, Abdelkarim MA. Consumers' perceptions on the contribution of community pharmacists in the dispensing process at Dawadmi. Saudi Pharm J. 2015;23:230-4.

34. Hussain A, Ibrahim MI. Perceptions of dispensers regarding dispensing practices in Pakistan: a qualitative study. Trop J Pharm Res. 2011;10:117-23

35. Peterson GM, Wu MSH, Bergin JK. Pharmacists' attitudes towards dispensing errors: their causes and prevention. J Clin Pharm Ther. 1999;24:57-71.

36. Cordina M, Safta V, Ciobanu A, Sautenkova N. An assessment of community pharmacists' attitudes towards professional practice in the Republic of Moldova. Pharm Pract (Granada). 2008;6:1-8.

37. Ansah EK, Narh-Bana S, Affran-Bonful H, Bart-Plange C, Cundill B, Gyapong $\mathrm{M}$, et al. The impact of providing rapid diagnostic malaria tests on fever management in the private retail sector in Ghana: a cluster randomized trial. BMJ. 2015;350:h1019.

38. Ghana Health Service. National Malaria Control Programme (NMCP) 2017. 2017;(9):1-12.

39. Brugha R, Chandramohan D, Zwi A. Viewpoint: management of malariaworking with the private sector. Trop Med Int Health. 1999;4:402-6.

40. Takala-Harrison S, Laufer MK. Antimalarial drug resistance in Africa: key lessons for the future. Ann NY Acad Sci. 2015;1342:62-7.

41. Rusk A, Smith N, Menya D, Obala A, Simiyu C, Khwa-Otsyula B, et al. Does anti-malarial drug knowledge predict anti-malarial dispensing practice in drug outlets? A survey of medicine retailers in western Kenya. Malar J. 2012;11:1-9.

\section{Publisher's Note}

Springer Nature remains neutral with regard to jurisdictional claims in published maps and institutional affiliations.
Ready to submit your research? Choose BMC and benefit from:

- fast, convenient online submission

- thorough peer review by experienced researchers in your field

- rapid publication on acceptance

- support for research data, including large and complex data types

- gold Open Access which fosters wider collaboration and increased citations

- maximum visibility for your research: over $100 \mathrm{M}$ website views per year

At BMC, research is always in progress.

Learn more biomedcentral.com/submissions 